\title{
Memória
}

\section{Juliano Moreira: um psiquiatra negro frente ao racismo científico}

Juliano Moreira (1873-1933), baiano de Salvador, é freqüentemente designado como fundador da disciplina psiquiátrica no Brasil. Sua biografia justifica tal eleição: mestiço (mulato), de família pobre, extremamente precoce, ingressou na Faculdade de Medicina da Bahia aos 13 anos, graduando-se aos 18 anos (1891), com a tese "Sífilis maligna precoce". Cinco anos depois, era professor substituto da seção de doenças nervosas e mentais da mesma escola. De 1895 a 1902, freqüentou cursos sobre doenças mentais e visitou muitos asilos na Europa (Alemanha, Inglaterra, França, Itália e Escócia). ${ }^{1}$

De 1903 a 1930, no Rio de Janeiro, dirigiu o Hospício Nacional de Alienados. Neste, embora não fosse professor da Faculdade de Medicina do Rio, recebia internos para o ensino de psiquiatria. Aglutinou ao seu redor médicos que viriam a ser, eles também, organizadores ou fundadores na medicina brasileira, de diversas especialidades: neurologia, psiquiatria, clínica médica, patologia clínica, anatomia patológica, pediatria e medicina legal, tais como Afrânio Peixoto, Antonio Austragésilo, Franco da Rocha, Ulisses Viana, Henrique Roxo, Fernandes Figueira, Miguel Pereira, Gustavo Riedel e Heitor Carrilho, entre outros. ${ }^{2}$

Um aspecto marcante na obra de Juliano Moreira foi sua explícita discordância quanto à atribuição da degeneração do povo brasileiro à mestiçagem, especialmente a uma suposta contribuição negativa dos negros na miscigenação. A posição de Moreira era minoritária entre os médicos, na primeira década do século XX, época em que ele mais diretamente se referiu a esta divergência, polemizando com o médico maranhense Raimundo Nina Rodrigues (1862-1906). Também desafiava outro pressuposto comum à época, de que existiriam doenças mentais próprias dos climas tropicais.,

Convém ressaltar que a teoria da degenerescência nunca seria colocada em questão por Moreira, mas apenas os seus fatores causais. Para ele, na luta contra as degenerações nervosas e mentais, os inimigos a combater seriam o alcoolismo, a sífilis, as verminoses, as condições sanitárias e educacionais adversas, enfim; o trabalho de higienização mental dos povos, disse ele, não deveria ser afetado por "ridículos preconceitos de cores ou castas (...)". 4

Em seu discurso de posse, ao ser aprovado no concurso para professor da Faculdade de Medicina da Bahia, em maio de 1896, Moreira descreveu de forma tão elegante quanto contundente o que parece ser sua experiência pessoal com relação ao marcante preconceito de cor na sociedade brasileira de então. Endereçando-se “(...) a quem se arreceie de que a pigmentação seja nuvem capaz de marear o brilho desta faculdade (...)", disse: "Subir sem outro bordão que não seja a abnegação ao trabalho, eis o que há de mais escabroso. (...) Em dias de mais luz e hombridade o embaçamento externo deixará de vir à linha de conta. Ver-se-á, então que só o vício, a subserviência e a ignorância são que tisnam a pasta humana quando a ela se misturam (...). A incúria e o desmazelo que petrificam (...) dão àquela massa humana aquele outro negror (...)"22 (págs.17-18).

Resumidamente, pode-se dizer que, de meados do século XIX até cerca de 1910, o país se definia prioritariamente pela raça, isto é, as discussões sobre o caráter nacional e o futuro da nação passavam pela solução dos problemas atribuídos à miscigenação do povo brasileiro. A partir da década de 1910, e especialmente após o fim da Primeira Guerra Mundial, o movimento pelo saneamento rural do Brasil ganhou força, e se deslocou o foco para a doença ou as doenças dos brasileiros. Um Brasil desconhecido seria revelado a partir de expedições de órgãos do governo, como as de Cândido Rondon, do Mato Grosso ao Amazonas, em 1907 e 1908, e as expedições científicas de Oswaldo Cruz. A famosíssima frase do médico Miguel Pereira, “O Brasil é um imenso hospital”, dita em 1916, marcou o início deste movimento. A exprobração à mestiçagem e ao nosso clima tropical cedeu lugar à condenação ao governo por abandonar as populações interioranas; seu atraso passou a ser atribuído ao isolamento geográfico e às infestações por doenças parasitárias, especialmente ancilostomose e doença de Chagas. Ao mesmo tempo, intensas campanhas sanitárias eram coordenadas por Oswaldo Cruz, contra a febre amarela e contra a varíola, doenças que espantavam muitos visitantes e imigrantes do Brasil. A doença tornou-se a chave para a identificação do Brasil, a higienização sua possibilidade de redenção. ${ }^{5} \mathrm{~A}$ ciência, mais especificamente a medicina, tendeu, então, a se autorepresentar como norteadora do processo de definição da nacionalidade e da modernização do país. ${ }^{6}$

O contexto político e cultural de sua época deve ser considerado quando se analisa a obra e a atuação de Juliano Moreira. Ele alinhou-se às correntes que então representavam a modernização teórica da psiquiatria e da prática asilar. Demonstrou isto em sua filiação à escola psicopatológica alemã - foi divulgador da obra de Kraepelin - e nas mudanças que introduziu quando assumiu o Hospício Nacional de Alienados.

Como ele mesmo descreveu, foram estas as mudanças: instalação de laboratórios de anatomia patológica e de bioquímica no hospital; remodelação do corpo clínico, com entrada de psiquiatras/neurologistas e outros especialistas (de clínica médica, pediatria, oftalmologia, ginecologia e odontologia); a abolição do uso de coletes e camisas de força; a retirada de grades de ferro das janelas; a preocupação com a formação dos enfermeiros; o grande cuidado com os registros administrativos, estatísticos e clínicos, entre outros. Sua atuação institucional incluiu a organização da "Assistência aos Alienados", mais tarde Serviço Nacional de Assistência aos Psico- 
patas, tendo redigido, em 1903, uma proposta de reforma do Hospício Nacional e insistido junto ao governo para a aprovação da legislação federal de assistência aos alienados, promulgada em 22/12/1903.,8

Sua extensa obra escrita abrangeu várias áreas de interesse; inicialmente, publicou estudos nas áreas de sifiligrafia, dermatologia, infectologia e anatomia patológica. A seguir, concentrou-se cada vez mais nas doenças nervosas e mentais, em descrições clínicas e terapêuticas, escreveu sobre modelos assistenciais e sobre a legislação referente aos alienados, discutiu a nosografia psiquiátrica e estudou as histórias da medicina e da assistência psiquiátrica no Brasil. Tinha especial interesse pela então chamada "psiquiatria comparada", ou seja, as manifestações das doenças mentais em culturas diversas, como atesta a sua correspondência com Emil Kraepelin. ${ }^{9}$

Seu espírito aberto e inquieto não ignorou a psicanálise; tendo domínio do alemão, conhecia as obras de Freud e tinha uma avaliação crítica delas. Numa resenha em que elogiou o livro de Franco da Rocha, "O pansexualismo na doutrina de Freud" (1920), referiu que a Sociedade Brasileira de Neurologia vinha promovendo palestras de divulgação da psicanálise e comentou, com sua ironia peculiar, que esta era pouco conhecida no país porque "No Brasil, em geral os colegas, em obediência à lei do menor esforço, aguardam que as idéias e as doutrinas pas-

\section{Referências}

1. Carvalhal LA. Loucura e Sociedade: o pensamento de Juliano Moreira (1903-1930) [monografia de bacharelado em História]. Rio de Janeiro: Universidade Federal do Rio de Janeiro; 1997.

2. Passos A. Juliano Moreira (vida e obra). Rio de Janeiro: Livraria São José; 1975.

3. Moreira J, Peixoto A. Les maladies mentales dans le climats tropicaux. Arq Bras Psiquiatr Neurol Ciênc Afins 1906;II(1):222-41.

4. Moreira J. A luta contra as degenerações nervosas e mentais no Brasil (comunicação apresentada no Congresso Nacional dos Práticos). Brasil Médico 1922;II:225-6.

5. Lima NT, Hochman G. Condenado pela raça, absolvido pela medicina: o Brasil descoberto pelo movimento sanitarista da primeira república. In: Maio MC, Santos RV, organizadores. Raça, Ciência e Sociedade. Rio de Janeiro: Fiocruz; 1996. p.23-40. sem primeiro pelo filtro francês para que nos dignemos a olhálas contra a luz (...)". ${ }^{10}$

Ao longo de toda sua vida, participou de muitos congressos médicos e representou o Brasil no exterior, na Europa e no Japão. Foi membro de diversas sociedades médicas e antropológicas internacionais; fundou, em colaboração com outros médicos, os periódicos Arquivos Brasileiros de Psiquiatria, Neurologia e Medicina Legal (1905), Arquivos Brasileiros de Medicina (1911) e Arquivos do Manicômio Judiciário do Rio de Janeiro (1930) e a Sociedade Brasileira de Psiquiatria, Neurologia e Medicina Legal (1907).

Finalizando, para melhor entender a atuação de Juliano Moreira deve-se recordar que, nas primeiras décadas do século $\mathrm{XX}$, a medicina brasileira acreditava ser capaz de dirigir o processo de modernização e sanitarização do país. Assim também cria Juliano Moreira e sua atuação foi coerente com esta visão; para ele, o principal papel da psiquiatria estava na profilaxia, na promoção da higiene mental e da eugenia. Em que pese o caráter francamente intervencionista deste projeto médico, não se pode negar o brilhantismo, a coragem e a originalidade deste fundador da psiquiatria brasileira.

\section{Ana Maria Galdini Raimundo Oda e Paulo Dalgalarrondo Departamento de Psicologia Médica e Psiquiatria da Faculdade de Ciências Médicas da Unicamp}

6. Schwarcz LM. O espetáculo da miscigenação. In: O espetáculo das raças: cientistas, instituições e questão racial no Brasil, 1870-1930. São Paulo: Companhia das Letras; 1993. p.11-22.

7. Moreira J. Notícia sobre a evolução da assistência a alienados no Brasil (1905b). Arq Bras Neuri Psiquiatr 1955; edição especial.

8. Arquivos do Manicômio Judiciário do Rio De Janeiro - Professor Juliano Moreira. Arq do Manicômio Judiciário do Rio de Janeiro 1933;IV(1-2):3-20.

9. Dalgalarrondo P. Cartas de Juliano Moreira a Emil Kraepelin. In: Civilização e Loucura: Uma Introdução à História da Etnopsiquiatria. São Paulo: Lemos; 1996. p.117-24.

10. Moreira J. Resenha de $O$ pansexualismo na doutrina de Freud, de Franco da Rocha. Brasil Médico 1920;XXIII (6):365-6. 